\title{
(6) OPEN ACCESS \\ Socioeconomic differences in the benefits of structured physical activity compared with health education on the prevention of major mobility disability in older adults: the LIFE study
}

\author{
David Bann, ${ }^{1}$ Haiying Chen, ${ }^{2}$ Chris Bonell, ${ }^{3}$ Nancy W Glynn, ${ }^{4}$ Roger A Fielding, ${ }^{5}$ \\ Todd Manini, ${ }^{6}$ Abby C King, ${ }^{7}$ Marco Pahor, ${ }^{8}$ Shannon L Mihalko, ${ }^{9}$ Thomas M Gill, ${ }^{10}$ \\ the Life Study investigators
}

\begin{abstract}
- Additional material is published online only. To view please visit the journal online (http://dx.doi.org/10.1136/jech2016-207321).
\end{abstract}

For numbered affiliations see end of article.

\section{Correspondence to} Dr David Bann, Centre for Longitudinal Studies, UCL Institute of Education, London WC1B 5JU, UK

david.bann@ucl.ac.uk

Received 2 February 2016 Revised 17 March 2016 Accepted 21 March 2016 Published Online First 8 April 2016

\section{CrossMark}

\author{
To cite: Bann $\mathrm{D}$, Chen $\mathrm{H}$, \\ Bonell $C_{\text {, et al. J Epidemiol }}$ \\ Community Health \\ 2016:70:930-933.
}

\begin{abstract}
Background Evidence is lacking on whether healthbenefiting community-based interventions differ in their effectiveness according to socioeconomic characteristics. We evaluated whether the benefit of a structured physical activity intervention on reducing mobility disability in older adults differs by education or income.

Methods The Lifestyle Interventions and Independence for Elders (LIFE) study was a multicentre, randomised trial that compared a structured physical activity programme with a health education programme on the incidence of mobility disability among at-risk communityliving older adults (aged 70-89 years; average follow-up of 2.6 years). Education ( $\leq$ high school (0-12 years), college (13-17 years) or postgraduate) and annual household income were self-reported ( $<\$ 24999$, $\$ 25000$ to $\$ 49999$ and $\geq \$ 50000$ ). The risk of disability (objectively defined as loss of ability to walk $400 \mathrm{~m}$ ) was compared between the 2 treatment groups using Cox regression, separately by socioeconomic group. Socioeconomic groupxintervention interaction terms were tested.
\end{abstract}

Results The effect of reducing the incidence of mobility disability was larger for those with postgraduate education $(0.72,0.51$ to $1.03 ; \mathrm{N}=411)$ compared with lower education (high school or less $(0.93,0.70$ to 1.24 ; $\mathrm{N}=536$ ). However, the education groupxintervention interaction term was not statistically significant $(p=0.54)$. Findings were in the same direction yet less pronounced when household income was used as the socioeconomic indicator.

Conclusions In the largest and longest running trial of physical activity amongst at-risk older adults, intervention effect sizes were largest among those with higher education or income, yet tests of statistical interactions were non-significant, likely due to inadequate power. Trial registration number NCT01072500.

\section{INTRODUCTION}

There is a recognised need to evaluate whether the benefits of community-based interventions differ by socioeconomic group. $^{1-3}$ To the authors' knowledge, no prior study has evaluated whether the effectiveness of interventions to prevent mobility disability among older adults differs according to socioeconomic group. This is important to investigate given the substantial individual and societal costs of mobility disability, ${ }^{4}$ and the observed differences in disability risk across socioeconomic groups: older adults with lower education or lower income, on average, have worse physical performance levels ${ }^{5}$ and a higher risk of mobility disability; ${ }^{7}{ }^{8}$ interventions may either widen or narrow these differences. ${ }^{12}$

Recent findings from the largest and longest duration randomised trial of physical activity in older adults demonstrated that a structured physical activity intervention-relative to a health education intervention-reduced the incidence of major mobility disability by $18 \%$ among at-risk community-living older adults (HR $0.82,95 \%$ CI 0.69 to 0.98$).{ }^{9}$ We investigated whether the benefits of this intervention differed by socioeconomic group and hypothesised that the benefits would be more pronounced among more socioeconomically advantaged groups, since greater socioeconomic resources may foster exercise participation and protect against adverse events and illnesses that could impede exercise. ${ }^{10} 11$

\section{METHODS}

Study sample

The Lifestyle Interventions and Independence for Elders (LIFE) study was a phase 3 randomised controlled trial conducted at eight field centres in eight US states. The rationale, design and methods of the LIFE study have been presented in detail elsewhere, ${ }^{12}$ as have baseline characteristics. ${ }^{13}$ Participants aged 70-89 years were eligible if they were at increased risk of mobility disability (ie, a Short Physical Performance Battery score $\leq 9$ ), yet were able to walk $400 \mathrm{~m}$ at their usual pace in 15 min without sitting, leaning or assistance from a walker/another person. Participants were additionally required to be relatively sedentary (ie, reported $<20 \mathrm{~min} /$ week in the past month getting regular physical activity and $\leq 125 \mathrm{~min} /$ week of moderate activity). The two self-reported socioeconomic indicators were education attainment $(\leq$ high school (0-12 years), college (13-17 years) or postgraduate) and annual household income $(<\$ 24999, \$ 25000$ to $\$ 49999$ and $\geq \$ 50000$ ). In total, 1635 participants $(\sim 67 \%$ women $)$ were randomised, ranging from 200 to 216 per site. Ethical approval was provided by the Institutional Review Boards, and written informed consent obtained from all study participants. 
The physical activity intervention consisted of moderateintensity- walking (with a $150 \mathrm{~min}$ goal per week), and strength, flexibility and balance training, in supervised clinical centres and at participants' homes. The comparison arm was a health education programme comprising workshops (weekly for the first 26 weeks, then monthly thereafter) on topics (excluding physical activity) such as nutrition, healthcare systems and safe travel.

The primary outcome of the LIFE study was major mobility disability, objectively defined as loss of ability to walk $400 \mathrm{~m}$. Persistent mobility disability was defined as two consecutive assessments with major mobility disability or major mobility disability followed by death. Participants were followed up every 6 months for an average of 2.6 years-from the time of enrolment and start of the interventions (February 2010 to December 2011) to the end of the interventions (December 2013).

We compared baseline demographic and health characteristics across socioeconomic groups, then compared the risk of mobility disability in each treatment group according to education or income using Cox regression models. We formally tested these differences through education or income $\times$ intervention interaction terms. ${ }^{14} 15$

\section{RESULTS}

Participants with higher compared with lower education were more frequently male, and had a lower prevalence of hypertension, yet they did not consistently differ with respect to measured physical performance (table 1-income results shown in online supplementary table). The effect estimates-showing the effect of physical activity on reducing the incidence of mobility disability-were greatest among participants with postgraduate education (HR 0.72 , 95\% CI 0.51 to 1.03 ) and weaker for those with intermediate $(0.81,0.61$ to 1.06$)$ or lowest education $(0.93,0.70$ to 1.24 ; table 2$)$, yet CIs overlapped. These differences were similar for persistent mobility disability. The education group $\times$ intervention interaction term was not statistically significant for either outcome $(p=0.54$ and 0.62 , respectively). Differences in effect sizes by household income were similar (table 2), and income $\times$ intervention interaction terms were also not statistically significant ( $p=0.90$ and 0.79 , respectively).

\section{DISCUSSION}

In the largest and longest running trial of physical activity among at-risk older adults, we found no statistically significant evidence that the benefits of physical activity on reducing the risk of mobility disability differed by education or income group. The lack of differential benefit indicates that this form of intervention, if established more widely across the country, would neither widen nor narrow socioeconomic inequalities in disability incidence. However, because intervention effect sizes were largest among those with higher education or income and because the trial was unlikely to have been adequately powered to detect statistically significant interactions, it is possible that the intervention could widen socioeconomic differences in disability incidence.

Despite the large size of the LIFE study (with 246 participants experiencing major mobility disability), it may still have been underpowered to detect genuine differences in intervention benefit across socioeconomic groups, since tests for interaction require particularly high statistical power ${ }^{14}{ }^{15}$-more power than is required to test for a main intervention effect across all

Table 1 Descriptive statistics of the LIFE study sample at baseline, by education group

\begin{tabular}{|c|c|c|c|c|c|c|c|c|}
\hline \multirow[b]{2}{*}{ Characteristic } & \multicolumn{4}{|c|}{ Physical activity group } & \multicolumn{4}{|c|}{ Health education group } \\
\hline & $\begin{array}{l}\leq \text { High school } \\
(\mathrm{K}-12)\end{array}$ & $\begin{array}{l}\text { College } \\
(13-17)\end{array}$ & Postgraduate & p Value* & $\begin{array}{l}\leq \text { High school } \\
(\mathrm{K}-12)\end{array}$ & $\begin{array}{l}\text { College } \\
(13-17)\end{array}$ & Postgraduate & p Value* \\
\hline $\mathrm{N}(\%)$ & $273(33.4)$ & $345(42.2)$ & $199(24.4)$ & & $263(32.4)$ & $338(41.6)$ & $212(26.1)$ & \\
\hline Age (years) & $78.5(5.1)$ & $78.7(5.4)$ & $78.9(5.2)$ & 0.73 & $79.0(5.1)$ & $79.2(5.2)$ & $78.9(5.4)$ & 0.84 \\
\hline Women (\%) & $207(75.8)$ & $223(64.6)$ & $116(58.3)$ & 0.001 & $199(75.7)$ & $225(66.6)$ & $126(59.4)$ & 0.001 \\
\hline Race (\% non-white) & $85(31.4)$ & $68(19.8)$ & 37 (18.6) & 0.001 & $65(24.9)$ & 47 (13.9) & $40(19.0)$ & 0.003 \\
\hline Income $\geq \$ 50 k(\%)$ & $44(18.4)$ & $104(33.7)$ & $94(53.4)$ & 0.001 & $35(15.1)$ & $95(32.2)$ & $100(51.8)$ & 0.001 \\
\hline BMI $\left(\mathrm{kg} / \mathrm{m}^{2}\right)$ & $30.5(5.8)$ & $29.9(5.7)$ & $29.7(5.7)$ & 0.25 & $31.0(6.2)$ & $29.9(6.1)$ & $30.2(6.5)$ & 0.08 \\
\hline \multicolumn{9}{|l|}{ Conditions (\%) } \\
\hline Hypertension & $210(77.2)$ & $226(66.1)$ & $137(68.8)$ & 0.009 & $207(78.7)$ & $231(69.0)$ & $139(67.5)$ & 0.009 \\
\hline Diabetes & $88(32.4)$ & $86(25.0)$ & $42(21.1)$ & 0.02 & $80(30.4)$ & $92(27.3)$ & $60(28.7)$ & 0.80 \\
\hline Myocardial infarction & $25(9.2)$ & $24(7.0)$ & $11(5.5)$ & 0.31 & $20(7.6)$ & $27(8.0)$ & $21(10.0)$ & 0.60 \\
\hline Stroke & $23(8.5)$ & $21(6.1)$ & $13(6.5)$ & 0.51 & $15(5.7)$ & $24(7.1)$ & $13(6.2)$ & 0.77 \\
\hline Cancer & $55(20.2)$ & $73(21.3)$ & $50(25.1)$ & 0.42 & 49 (18.6) & $76(22.5)$ & $65(31.0)$ & 0.006 \\
\hline Chronic pulmonary disease & $54(19.8)$ & 45 (13.1) & 31 (15.6) & 0.08 & $48(18.3)$ & $44(13.1)$ & $30(14.3)$ & 0.21 \\
\hline 3MSE score, 0-100 scale & $89.5(5.7)$ & $92.0(5.2)$ & $93.5(4.8)$ & 0.001 & $89.6(5.8)$ & $91.9(4.8)$ & $93.7(4.7)$ & 0.001 \\
\hline $\begin{array}{l}\text { Walking/weight activities (min/ } \\
\text { week) }\end{array}$ & $77.3(134.5)$ & $63.1(106.8)$ & $92.1(140.6)$ & 0.032 & $84.6(131.3)$ & $85.8(137.2)$ & $90.1(134.4)$ & 0.90 \\
\hline Sedentary time (min/day) & $628.1(120.4)$ & $641.2(109.5)$ & $678.5(114.6)$ & 0.001 & $632.7(110.6)$ & $645.9(114.5)$ & $646.0(107.2)$ & 0.37 \\
\hline $\begin{array}{l}\text { Lower light-intensity activity } \\
\text { (min/day) }\end{array}$ & $173.7(54.5)$ & $160.7(51.1)$ & $152.1(53.0)$ & 0.001 & $172.5(51.5)$ & $158.6(57.1)$ & $160.5(52.8)$ & 0.02 \\
\hline $\begin{array}{l}\text { Higher light-intensity activity } \\
\text { (min/day) }\end{array}$ & $27.7(21.1)$ & $27.4(21.7)$ & $27.0(24.8)$ & 0.96 & $28.5(28.9)$ & $27.6(25.6)$ & $28.3(23.4)$ & 0.93 \\
\hline SPPB score & $7.4(1.5)$ & $7.5(1.6)$ & $7.5(1.6)$ & 0.83 & $7.3(1.6)$ & $7.3(1.6)$ & $7.4(1.6)$ & 0.65 \\
\hline $400 \mathrm{~m}$ walking speed, m/s & $0.8(0.2)$ & $0.8(0.2)$ & $0.8(0.2)$ & 0.06 & $0.8(0.2)$ & $0.8(0.2)$ & $0.8(0.2)$ & 0.50 \\
\hline
\end{tabular}


Table 2 HRs of major and persistent mobility disability for physical activity versus health education, by education or income group

\begin{tabular}{|c|c|c|c|c|c|c|}
\hline & \multicolumn{2}{|c|}{ Physical activity } & \multicolumn{2}{|c|}{ Health education } & \multirow[b]{2}{*}{ HR $(95 \% \mathrm{Cl})$} & \multirow[b]{2}{*}{ p (Interaction)* } \\
\hline & N & Number of events (\%) & $\mathrm{N}$ & Number of events (\%) & & \\
\hline \multicolumn{7}{|l|}{ Major mobility disability } \\
\hline \multicolumn{7}{|l|}{ Education } \\
\hline$\leq$ High school (0-12) & 273 & $95(34.8)$ & 263 & $93(35.4)$ & 0.93 (0.70 to 1.24$)$ & 0.54 \\
\hline College (13-16) & 345 & $96(27.8)$ & 338 & $119(35.2)$ & 0.81 (0.61 to 1.06 ) & \\
\hline Postgraduate (17+) & 199 & $55(27.6)$ & 212 & $75(35.4)$ & $0.72(0.51$ to 1.03$)$ & \\
\hline \multicolumn{7}{|l|}{ Income } \\
\hline$\leq \$ 24999$ & 230 & $77(33.5)$ & 232 & $87(37.5)$ & 0.86 (0.63 to 1.17$)$ & 0.90 \\
\hline$\$ 25000-\$ 49999$ & 252 & $75(29.8)$ & 258 & $94(36.4)$ & 0.77 (0.57 to 1.05$)$ & \\
\hline$\geq \$ 50000$ & 242 & $63(26)$ & 230 & $72(31.3)$ & $0.82(0.59$ to 1.16$)$ & \\
\hline \multicolumn{7}{|c|}{ Persistent mobility disability } \\
\hline \multicolumn{7}{|l|}{ Education } \\
\hline$\leq$ High school (0-12) & 273 & $51(18.7)$ & 263 & $57(21.7)$ & $0.83(0.57$ to 1.21$)$ & 0.62 \\
\hline College (13-16) & 345 & $41(11.9)$ & 338 & 59 (17.5) & 0.68 (0.45 to 1.01$)$ & \\
\hline Postgraduate (17+) & 199 & $28(14.1)$ & 212 & $46(21.7)$ & $0.63(0.39$ to 1.01$)$ & \\
\hline \multicolumn{7}{|l|}{ Income } \\
\hline$\leq \$ 24999$ & 230 & $36(15.7)$ & 232 & $48(20.7)$ & $0.78(0.5$ to 1.2$)$ & 0.79 \\
\hline$\$ 25000-\$ 49999$ & 252 & $37(14.7)$ & 258 & $50(19.4)$ & 0.71 (0.46 to 1.09$)$ & \\
\hline$\geq \$ 50000$ & 242 & $29(12)$ & 230 & $43(18.7)$ & 0.62 (0.39 to 0.99$)$ & \\
\hline
\end{tabular}

HR and interaction terms calculated using Cox regression.

${ }^{*} \mathrm{p}$ Values were derived from intervention $\times$ socioeconomic group interaction terms.

participants. For example, assuming a HR of 0.9 for low education and 0.75 for high education $(50 \%$ of participants in each group), and an $\alpha$ of 0.05 (two-sided), we calculate that 3776 events would be required to achieve $80 \%$ power to detect a statistically significant interaction $(p<0.05)$. In order to be sufficiently powered, future studies may therefore require larger sample sizes and/or be pooled into meta-analyses. In addition, the primary outcome of this study was mobility disability-a dichotomous outcome; studies using continuous outcomes are likely to have greater power to detect differences in intervention benefit.

Socioeconomic differences in enrolment and follow-up could also lead to socioeconomic differences in intervention benefit. Minimal loss to follow-up occurred in the LIFE study (4\% per year ${ }^{9}$ ), and recruitment was relatively successful (eg, 59.4\% of those contacted by mail ${ }^{13}$ ). However, we were unable to investigate socioeconomic differences in enrolment due to the lack of relevant data for non-responders. Other physical activity trials have reported lower enrolment among those of lower education or income, a pattern which could widen inequalities, ${ }^{16} 17$ yet efforts were made in the LIFE study to enable participation regardless of socioeconomic circumstances (eg, free transport provision for some participants) which may have limited this tendency.

Strengths of this study include the use of data from a large number of older adults with extensive follow-up across the USA and objective outcome assessment. Although both education and (banded) household income were available, future studies may include more refined socioeconomic measures which better distinguish socioeconomic groups and thereby enable greater power. ${ }^{1}$ For example, continuously measured disposable income and wealth may be especially relevant socioeconomic indicators in old age, ${ }^{18}$ while early life socioeconomic conditions may have independent effects on adult physical activity and disability risk. ${ }^{6} 20$

In the largest and longest running trial to date, we found that the benefits of a physical activity intervention in preventing mobility disability did not significantly differ by socioeconomic group, yet effect sizes of intervention benefit were largest among those with higher education or income. Our findings add to a limited number of existing studies, some of which found that physical activity interventions inadvertently increase inequalities in other outcomes at younger ages. ${ }^{2}$ These studies could ultimately be pooled to enable greater statistical power for subgroup interactions, and used to identify the characteristics of interventions which both improve average population health and reduce inequalities.

\section{What is already known on this subject}

- A large-scale multicentre randomised trial recently found that a physical activity intervention, compared with a health education programme, reduced disability incidence in at-risk community-dwelling older adults (the Lifestyle Interventions and Independence for Elders (LIFE) study).

- There is an important lack of evidence on whether health-benefiting interventions differ in their effectiveness by socioeconomic group.

\section{What this study adds}

- There was no statistically significant evidence that the benefits of physical activity on reducing the risk of mobility disability differed by education or income group, yet effect sizes of intervention benefit were largest among those with higher education or income.

- Despite being the largest physical activity trial yet conducted among older adults, there may have been inadequate power to detect genuine differences in benefit by socioeconomic group. Future studies may be designed to specifically evaluate potential socioeconomic differences in benefit, and/ or pool estimates from multiple studies. 


\section{Author affiliations}

${ }^{1}$ Centre for Longitudinal Studies, UCL Institute of Education, London, UK ${ }^{2}$ Division of Public Health Sciences, Department of Biostatistical Sciences, Wake Forest School of Medicine, Winston-Salem, North Carolina, USA

${ }^{3}$ Department of Social and Environmental Health, London School of Hygiene and Tropical, Medicine, UK

${ }^{4}$ Center for Aging and Population Health, Department of Epidemiology, University of Pittsburgh, Pittsburgh, PA, USA

${ }^{5}$ Nutrition, Exercise Physiology, and Sarcopenia Laboratory, Jean Mayer USDA Human Nutrition Research Center on Aging at Tufts University, Boston,

Massachusetts, USA

${ }^{6}$ Department of Aging \& Geriatric Research, University of Florida, Gainesville, Florida, USA

${ }^{7}$ Stanford University School of Medicine, Stanford, California, USA

${ }^{8}$ Department of Aging \& Geriatric Research, University of Florida, Gainesville, Florida, USA

${ }^{9}$ Department of Health and Exercise Science, Wake Forest University, Winston-Salem, North Carolina, USA

${ }^{10}$ Yale School of Medicine, New Haven, Connecticut, USA

Contributors DB and TMG conceived and designed the study and developed the study objectives. HC conducted all analyses. DB, TMG and HC contributed to the analytic strategy; all authors contributed to the interpretation of data, reviewed and revised the manuscript, and approved the final version for which they are accountable.

Funding DB is supported by the Economic and Social Research Council (grant code ES/M001660/1). The Lifestyle Interventions and Independence for Elders Study is funded by a National Institutes of Health/National Institute on Aging Cooperative Agreement \#U01AG22376 and a supplement from the National Heart, Lung and Blood Institute 3U01AG022376-05A2S, and sponsored in part by the Intramural Research Program, National Institute on Aging, NIH. A list of contributors to the LIFE study can be found at the following: https://thelifestudy.org/docs/LIFE-AcknowledgementList13_ 2014-07-17_Full\%20List_clean.pdf.

Competing interests None declared.

Ethics approval Ethical approval was provided by the Institutional Review Boards in the following centres: University of Florida, Northwestern University, Pennington Biomedical Research Center, University of Pittsburgh, Stanford University, Tufts University, Wake Forest University and Yale University.

Provenance and peer review Not commissioned; externally peer reviewed.

Data sharing statement Data are available on request to academic researchers from the following link: https://www.thelifestudy.org/public/index.cfm.

Open Access This is an Open Access article distributed in accordance with the terms of the Creative Commons Attribution (CC BY 4.0) license, which permits others to distribute, remix, adapt and build upon this work, for commercial use, provided the original work is properly cited. See: http://creativecommons.org/licenses/ by/4.0/

\section{REFERENCES}

1 Bonell C, Fletcher A, Morton M, et al. Realist randomised controlled trials: a new approach to evaluating complex public health interventions. Soc Sci Med 2012;75:2299-306.
2 Lorenc $T$, Petticrew $M$, Welch $V$, et al. What types of interventions generate inequalities? Evidence from systematic reviews. J Epidemiol Community Health 2013;67:190-3.

3 Humphreys DK, Ogilvie D. Synthesising evidence for equity impacts of population-based physical activity interventions: a pilot study. Int J Behav Nutr Phys Act 2013;10:76.

4 Hardy SE, Kang Y, Studenski SA, et al. Ability to walk 1/4 mile predicts subsequent disability, mortality, and health care costs. J Gen Intern Med 2011;26:130-5.

5 Birnie K, Cooper R, Martin RM, et al. Childhood socioeconomic position and objectively measured physical capability levels in adulthood: a systematic review and meta-analysis. PLOS ONE 2011;6:e15564.

6 Hurst L, Stafford M, Cooper R, et al. Lifetime socioeconomic inequalities in physical and cognitive ageing. Am J Public Health 2013;103:1641-8.

7 Schoeni RF, Martin LG, Andreski PM, et al. Persistent and growing socioeconomic disparities in disability among the elderly: 1982-2002. Am J Public Health 2005;95:2065-70.

8 Minkler M, Fuller-Thomson E, Guralnik JM. Gradient of disability across the socioeconomic spectrum in the United States. N Engl J Med 2006;355:695-703.

9 Pahor M, Guralnik JM, Ambrosius WT. Effect of structured physical activity on prevention of major mobility disability in older adults: the life study randomized clinical trial. JAMA 2014;311:2387-96.

10 Phelan JC, Link BG, Tehranifar P. Social conditions as fundamental causes of health inequalities: theory, evidence, and policy implications. J Health Soc Behav 2010;51 (Suppl):S28-40.

11 Gidlow C, Johnston LH, Crone D, et al. A systematic review of the relationship between socio-economic position and physical activity. Health Educ J 2006;65:338-67.

12 Fielding RA, Rejeski WJ, Blair $\mathrm{S}$, et al. The lifestyle interventions and independence for elders study: design and methods. J Gerontol A Biol Sci Med Sci 2011:66:1226-37.

13 Marsh AP, Lovato LC, Glynn NW, et al. Lifestyle interventions and independence for elders study: recruitment and baseline characteristics. J Gerontol A Biol Sci Med Sci 2013;68:1549-58.

14 Petticrew M, Tugwell P, Kristjansson E, et al. Damned if you do, damned if you don't: subgroup analysis and equity. I Epidemiol Community Health 2012;66:95-8.

15 Yusuf S, Wittes J, Probstfield J, et al. Analysis and interpretation of treatment effects in subgroups of patients in randomized clinical trials. JAMA 1991;266:93-8.

16 Martinson BC, Crain AL, Sherwood NE, et al. Population reach and recruitment bias in a maintenance RCT in physically active older adults. J Phys Act Health 2010;7:127.

17 Chinn DJ, White M, Howel D, et al. Factors associated with non-participation in a physical activity promotion trial. Public Health 2006;120:309-19.

18 Pollack CE, Chideya S, Cubbin C, et al. Should health studies measure wealth? A systematic review. Am J Prev Med 2007:33:250-64.

19 Demakakos P, Biddulph JP, Bobak M, et al. Wealth and mortality at older ages: a prospective cohort study. J Epidemiol Community Health 2015;70:346-53.

20 Elhakeem A, Cooper R, Bann D, et al. Childhood socioeconomic position and adult leisure-time physical activity: a systematic review. Int J Behav Nutr Phys Act 2015;12:92. 